\title{
Are textbooks facilitators or barriers for teachers' teaching and instructional change? An investigation of secondary mathematics teachers in Shanghai, China
}

\author{
Lianghuo Fan ${ }^{1,2}$ - Jing Cheng ${ }^{1} \cdot$ Sicheng Xie ${ }^{1}$ Jietong Luo ${ }^{1} \cdot$ Yisu Wang ${ }^{1} \cdot$ Yuxiang Sun $^{1}$
}

Accepted: 28 August 2021 / Published online: 11 September 2021

(c) FIZ Karlsruhe 2021

\begin{abstract}
In this paper we report on a survey study of teachers' perceptions of how mathematics textbooks, including broadly student books, teacher manuals, and exercise books, facilitate or hinder teachers' teaching in Shanghai educational settings. For the study we established a conceptual framework about teachers' teaching, partly drawing on Shulman's model of pedagogical reasoning and action of teachers. The data were collected from a stratified random sample of 133 mathematics teachers in 13 secondary schools through a questionnaire, and follow-up interviews with 24 of them. The results revealed the following: the textbooks were highly regarded and used by the Shanghai mathematics teachers as facilitators rather than barriers for their teaching and instructional change, and the facilitation was most evident in the process of transformation and comprehension, and least evident in evaluation in teachers' pedagogical reasoning and action; compared with student books and exercise books, teacher manuals played a larger facilitating role in teachers' teaching; and finally, compared with teacher characteristics, school characteristics had a greater influence on the extent to which textbooks played a role of facilitation or hindrance for teachers' instructional practice. Implications and suggestions are given at the end of the paper.
\end{abstract}

Keywords Instructional change $\cdot$ Role of mathematics textbooks $\cdot$ Pedagogical reasoning and action $\cdot$ Shanghai mathematics classroom

\section{Introduction}

The outstanding performance of Shanghai students as shown in the recent PISA tests (e.g., OECD, 2013, 2019), particularly in mathematics, has gained widespread attention at home and abroad from educational researchers, policy makers, and practitioners. Researchers have explored the reasons behind this result by looking into different aspects, such as classroom and pedagogical features (Boylan et al., 2018; Wu $\&$ Bao, 2016), culture and policy (Tan, 2013), contextual influences (Sellar \& Lingard, 2013; Zhang \& Kong, 2012), and textbooks or, more broadly, curriculum resources (Boylan et al., 2019; Oates, 2014; Wang \& Fan, 2021).

Although it is commonly acknowledged that mathematics textbooks play an essential role in the process of teaching

Lianghuo Fan

lhfan@math.ecnu.edu.cn

East China Normal University, Shanghai, China

2 University of Southampton, Southampton, UK and learning, especially in East Asian countries, most available relevant studies have concentrated generally on the textbooks themselves, and surprisingly, there have been virtually no studies focusing on how mathematics textbooks play a role in teachers' teaching in Shanghai educational settings. In this paper, we report on a survey study, as part of a larger study, to contribute to this line of research, investigating how textbooks play a role, as a facilitator or a barrier, in Shanghai mathematics teachers' teaching and instructional change. With a focus on secondary schools, the overarching research question is as follows:

To what extent do textbooksplay a facilitation or hindrance role in Shanghai teachers' teaching of mathematics?

In this study, considering the Shanghai context, the term 'textbooks' is broadly defined to include student (text) books, teacher manuals (guides), and student exercise books (hereafter 'exercise books'), as all mathematics teachers in Shanghai secondary schools are equipped with one student book, one teacher manual, and one exercise book for each 
grade they teach in a semester. Approved by the educational authorities, the standard books in this set are Shanghai teachers' essential instructional resources and hence are juxtaposed together to provide a relatively comprehensive picture of Shanghai teachers' teaching concerning the use of textbooks. Furthermore, under the overarching research question, we seek to determine if there exist differences between various groups of teachers concerning the role of textbooks in their teaching. Therefore, this study is also steered by the following two sub-questions derived from the general research question:

1. Do textbooks play a facilitation or hindrance role differently for different teachers in their teaching?

2. Do different types of textbooks play a facilitation or hindrance role differently in teachers' teaching of mathematics?

By addressing these questions, we hope not only to obtain a general picture of the role that textbooks play in Shanghai teachers' teaching of mathematics, and provide research evidence that contributes to filling the gap in the existing research literature, but also to shed light on how textbooks should be developed and used to better facilitate teachers' teaching of mathematics beyond the Shanghai educational settings.

\section{Literature review}

The issue about what role textbooks play in teachers' teaching is closely related to teachers' use of textbooks. The latter is one of the three main areas of empirical research centering around mathematics textbooks, as identified in a relatively comprehensive review on mathematics textbook research (Fan et al., 2013).

Concerning teachers' use of textbooks, researchers consistently pointed out that it had been under-studied for a long time, partly because of difficulty in collecting the empirical data (e.g., Fan, 2013; Love \& Pimm, 1996). Nevertheless, an increasing number of studies have been conducted in more recent years in this area ${ }^{1}$ (e.g., Lepik et al., 2015; Thompson \& Senk, 2014; Ulusoy \& Incikabi, 2020). Of these studies, some reported that differences in the use of textbooks may or may not exist across different groups of teachers (e.g., Jamieson-Proctor \& Byrne, 2008; Manouchehri \& Goodman, 2000). Moreover, some studies revealed that teachers had different levels of fidelity to different aspects in their use

\footnotetext{
${ }^{1}$ Readers who are interested in knowing more about earlier studies on teachers' use of textbooks may refer to the work reported by Fan et al. (2013).
}

of textbooks (e.g., Grouws et al., 2013; Johansson, 2017). From these studies, we can see that the issues relating to teachers' use of textbooks are complex and can have rather different patterns. In addition, most of these studies have focused on issues concerning the frequency or patterns of textbook use, with those concerning the effect of using the textbooks seemingly largely neglected.

Regarding the role of textbooks, it was commonly found that textbooks played an essential role in teachers' preparation and planning for lessons ( $\mathrm{Li}$ et al., 2009; Viholainen et al., 2015). They also had an impact on teachers' teaching behaviors, such as introducing new content and assigning homework (Gracin \& Matić, 2019), structuring teaching and learning (Sosniak \& Perlman, 1990), arranging in-class exercises (Pepin et al., 2013), teaching strategies (Fan \& Kaeley, 2000), and explanations and activities (Carnine, 1991).

Some researchers have also conducted studies on whether textbooks play different roles for different teachers in their teaching. For example, Lepik et al. (2015) found that teachers from different countries treated textbooks differently in responding to the question of whether or not textbooks served as their primary tool in lesson planning and preparation, which was regarded to be at least partially due to the effect of different traditions. Haggarty and Pepin (2017) found that compared with experienced teachers, less experienced teachers or non-specialist teachers relied more on textbooks because of the lack of time for lesson planning (see also O'Keeffe \& White, 2017). On the other hand, Johansson's study (2017) of three Swedish teachers revealed that despite the differences between these teachers, the textbooks played, to a large degree, a similarly guiding role in their teaching.

It should be stressed that although issues of how textbooks are used by teachers and what role textbooks play in teachers' teaching are closely related, they are not identical, as the former is in a sense neutral or value-free (e.g., regarding patterns of use), but the latter involves a further value judgement, especially when it comes to the issue of whether textbooks play a facilitation or hindrance role in teachers' teaching. Nevertheless, in the previous literature, this value judgement was rarely examined.

As key teaching materials, textbooks are intended to be used in different stages of teaching. As Shulman (1987) pointed out: "The text may be a vehicle for the accomplishment of other educational purposes, but some sort of teaching material is almost always involved" (p. 14). According to Shulman, in general, teachers' teaching is initiated by some form of 'text' - a textbook or other teaching materials-and their pedagogical reasoning and actions for teaching involve a cycle through the activities of 'comprehension', 'transformation', 'instruction', 'evaluation', 'reflection' and 'new comprehension' (see more details below); moreover, educational materials (including textbooks) and structures 
"comprise both the tools of the trade and the contextual conditions that will either facilitate or inhibit teaching efforts" (p. 10, emphasis added). This aspect leads to the issue of whether textbooks facilitate or hinder the processes of teachers' pedagogical reasoning and actions.

There are a few studies addressing, implicitly or explicitly, issues concerning the facilitating or hindering role of textbooks in the aforementioned processes of teachers' teaching of mathematics. For example, focusing on 'comprehension', Ding et al. (2013) found that Chinese textbooks may help teachers to acquire directly the knowledge that ' 0 cannot be a divisor', while Davis (2009) argued that the two US textbooks in his study generally had little effect on teachers' understanding of exponent properties. Furthermore, an analysis of a popular set of textbooks for upper primary mathematics in Spain found that mathematics textbooks may become an obstacle when learning the topic of measure, since these textbooks show a very skewed approach to the teaching of this topic (Mengual et al., 2015).

With regard to 'transformation', it was reported that Canadian post-secondary teachers regarded textbooks as 'good resources' in sequencing and presenting the content as well as selecting exercises in their lesson planning (GonzálezMartín et al., 2018). On the other hand, contrasting results about the role of textbooks (including teacher guides), as a facilitator or barrier, concerning teachers' teaching methods were discovered (e.g., Davis, 2009; Matić \& Gracin, 2021; Ulusoy \& Incikabi, 2020). Based on the TIMSS Video Study criteria, Vincent and Stacey (2008) claimed that features of some best-selling Australian textbooks can be seen contributing to the low-procedural complexity, highly-repetitive, lack-of-reasoning mode of teaching, also known as 'shallow teaching'.

In terms of 'instruction', it was reported that teachers' use of examples of textbooks might help their students overcome difficulties (Davis, 2009; González-Martín et al., 2018) and engage in active knowledge organization (Prediger et al., 2021). Furthermore, regarding assessment or 'evaluation' in Shulman's terms, some researchers found that textbooks provided problems and applications that were helpful (O'Keeffe $\&$ White, 2017) or not so helpful (Divrik et al., 2020) for teachers' assessment and evaluation, and textbooks could also serve as a reference in teachers' 'reflection' on their teaching, which was the case in a Shanghai teaching research group's attempt to support a junior teacher's professional learning (Ding et al., 2017).

It is worth noting that researchers have also pointed out that textbooks could play an important role in mathematics education reform (Carnine, 1991; Gravemeijer, 2014), as reform textbooks could reflect the ideas of curriculum reforms (Martin et al., 2001). For example, Kilpatrick (2012) argued that 'new math' reformers in many countries brought their ideas into schools through textbooks and other instructional materials, while Nie et al. (2013) compared the role of reform standards-based and traditional textbooks used by mathematics teachers in the US and argued that these two series of textbooks played a different role in teachers' intended learning goals.

To summarize, earlier research revealed that textbooks largely played an important role in supporting teachers' mathematics instruction in different countries, but different patterns existed among different countries and different teachers, and in some cases, textbooks did not offer help and instead caused hindrance for teachers' teaching. Most studies were of small scale, based on self-report data, and almost all using non-random samples. Overall, existing studies either focused on the pattern of using textbooks without specifying the impact of their use, or paid attention only to the facilitation or hindrance of textbooks on some aspects or processes of mathematics teaching rather than giving a whole picture of it. Thus, more specific and systematic research is needed in this area. Finally, there has been little research focusing on how mathematics textbooks play a role in teachers' teaching in Chinese-let alone Shanghai-educational settings.

\section{Methodology}

To examine how mathematics textbooks facilitate or hinder Shanghai teachers' teaching, we established a conceptual framework, drawing partly on Shulman's (1987) model of pedagogical reasoning and action, and employing both qualitative and quantitative methods.

\subsection{Conceptual framework}

As aforementioned, Shulman's (1987) pedagogical reasoning and action framework consists of a cycle of the following processes: (1) Comprehension of what is to be taught, including that of purpose, subject matter structures, and ideas within and outside the discipline, in a critical way; (2) Transformation of the comprehended ideas into manners suitable for teaching, which requires a combination of preparation, representation, selection, adaptation, and tailoring them to students' characteristics; (3) Instruction, which refers to the observable forms of classroom teaching, such as management, presentation, and questioning; (4) Evaluation of students during interactive teaching or summative feedback, as well as teachers' own performance; (5) Reflection, which involves looking back at what has occurred in teaching and learning, and then reconstructing, reenacting, and/ or recapturing teachers' and students' performance. After these processes, teachers achieve new comprehension of the purposes, the subjects to be taught, the students, and the processes of pedagogy themselves, and thus start a new cycle. 
We have three reasons to draw partly on Shulman's (1987) theoretical model. First, earlier research (Fan et al., 2004) and, in fact, our personal experiences about mathematics teachers in different secondary schools in Shanghai and other parts of China, have made us aware that textbooks are most commonly involved in the whole process of Chinese teachers' teaching, that is, activities before, during, and after class such as lesson planning, in-class questioning, and after-class evaluation and reflection, which suggests the need for a framework systematically covering all activities of the whole process; in comparison, most of the previous frameworks focused on particular aspects for different purposes (e.g., Brown, 2009; Remillard, 2005). Second, as Shulman's model addresses the whole cycle of teachers' teaching, it can help us to look into how textbooks play a role in their teaching in a comprehensive manner, which is an important purpose of our study. Third, as in many other countries, teachers' professional learning and reflective teaching have received increasing attention in China's new curriculum reform, which started from the beginning of the twentyfirst century (China Ministry of Education, 2011; Shanghai Municipal Education Commission, 2004), and Shulman's model, integrating pedagogical reasoning and action of teaching, is in alignment with such a reform philosophy that emphasizes teachers' reflective or inquiry teaching (see also Darling-Hammond, 2006). Therefore, we believe examining how textbooks, essential in Chinese teachers' teaching, play a role as facilitators or barriers in their pedagogical reasoning for teaching is not only necessary, but also timely.

Having said the above, we must point out that, to serve the purpose of this study, some adaptations of Shulman's theoretical model are necessary, given that it is not specifically for the teaching of mathematics, let alone the use of mathematics textbooks, nor was it specifically formulated for Chinese educational settings.

Specifically, a few components in Shulman's model were excluded in this study as they were not applicable in the context of mathematics classroom or textbook use, and in particular, the component 'new comprehension' was not included, because in terms of Shulman's conceptualization, this component is more pertinent to teachers' knowledge growth and for the beginning of the next cycle of action. Moreover, some components were adapted in terms of the mathematics education context (e.g., ideas within and outside mathematics). Furthermore, some components (e.g., the ideas of Shanghai/Chinese curriculum reform) were included to take into account the educational contexts of China and Shanghai.

Table 1 shows the conceptual framework, partly drawing on Shulman's model with adaptation to the teaching of mathematics and to the educational contexts in Shanghai, including the mathematics curriculum reform, as mentioned above. For illustrative purposes, concrete examples are given in the table.

\subsection{Sample}

For a better representativeness of sample, we applied a multi-stage stratified random sampling method in a highly strict manner by first selecting districts, then schools, and finally, teachers.

First, we randomly selected 10 districts from all 16 districts in Shanghai. Then, we classified all the 528 secondary schools $^{2}$ in the 10 districts into two categories in each district: high-performing schools and ordinary schools, based on the lists of high-performing schools in all but one of the 10 districts published on a local educational website. ${ }^{3}$ For the district with no such list on the website, we invited a teaching research fellow in the district's Education Bureau to help identify the high-performing schools in the district. The results of classification were validated by local educational experts.

We then randomly selected a high-performing school and an ordinary school from the two categories in each district and in total, 10 high-performing and 10 ordinary schools were selected and invited to take part in the study. Due to various reasons including the impact of the COVID-19 pandemic, five high-performing schools and eight ordinary schools from nine districts agreed to participate.

To collect the data, we distributed the questionnaire to all 137 mathematics teachers in the 13 schools and received it back from 133 of them. Among them, 24 teachers were further interviewed (see more details below). Table 2 provides a profile of the participating teachers.

\subsection{Research instruments}

Based on the conceptual framework, a questionnaire was designed mainly to obtain quantitative data, and this was followed by a structured interview designed to obtain more qualitative and in-depth information.

The questionnaire consisted of three parts. ${ }^{4}$ Part one collected teachers' demographic information, or teacher characteristics, including gender, age, teaching experience, educational backgrounds, and locations of their schools.

Part two was designed in line with the features of the Shanghai mathematics textbooks. Using a 4-point Likert

\footnotetext{
${ }^{2}$ In Shanghai, secondary education comprises 4 years from grades 6-9. Some schools in this study also offer primary education from grades $1-5$. Only secondary teachers were included in the study.

${ }^{3}$ https://edu.online.sh.cn/education/gb/content/2019-11/19/content_ 9439937.htm.

4 The English version of the questionnaire can be seen in Online Resource 2.
} 


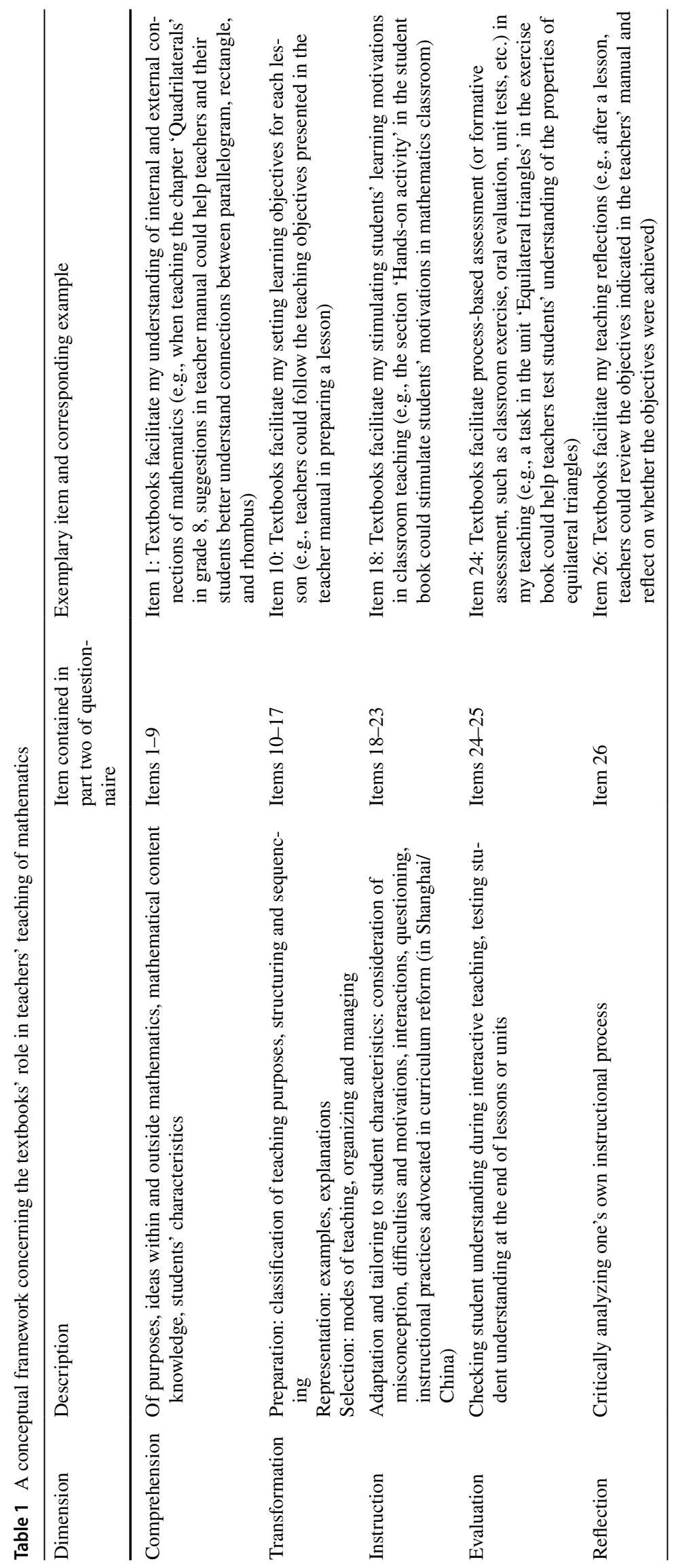


Table 2 Profile of participating teachers* $(N=133)$

\begin{tabular}{|c|c|c|c|c|c|c|c|c|c|c|c|c|c|c|}
\hline & \multicolumn{6}{|c|}{ School characteristic } & \multicolumn{8}{|c|}{ Teacher characteristic } \\
\hline & \multicolumn{2}{|c|}{ School level } & \multicolumn{2}{|c|}{ School type } & \multicolumn{2}{|c|}{ School location } & \multicolumn{2}{|c|}{ Gender } & \multicolumn{3}{|c|}{$\begin{array}{l}\text { Length of teaching } \\
\text { experience (years) }\end{array}$} & \multicolumn{3}{|c|}{ Highest qualification } \\
\hline & $\begin{array}{l}\text { High-per- } \\
\text { forming }\end{array}$ & Ordinary & Public & Private & Urban & Suburban & M & $\mathrm{F}$ & $(0,10)^{* *}$ & $(10,20)$ & $>20$ & Diploma & Bachelor & Master \\
\hline Number & 59 & 74 & 93 & 40 & 64 & 69 & 35 & 98 & 45 & 41 & 47 & 1 & 107 & 25 \\
\hline$\%$ & 44.4 & 55.6 & 69.9 & 30.1 & 48.1 & 51.9 & 26.3 & 73.7 & 33.8 & 30.8 & 35.3 & 0.8 & 80.5 & 18.8 \\
\hline
\end{tabular}

*More detailed information is given in Online Resource 1

**10 years or less

scale (4 for 'strongly agree' and 1 for 'strongly disagree'), all 26 items in this part aimed to reveal how the textbooks facilitated teachers' teaching in the five different dimensions (or components in Shulman's terms): comprehension, transformation, instruction, evaluation, and reflection (see Table 1). Details concerning each item can also be seen in Tables 3, 4, 5, and 6 .

The last part comprised two open-ended questions (OEQ). OEQ 1 asked teachers to describe whether textbooks facilitated their teaching in one of their recent lessons and, if so, to give one concrete example, while OEQ 2 asked them to describe whether textbooks failed to facilitate or even hindered their teaching.

The structured interview was designed to gather indepth information by asking teachers questions focusing on whether and how textbooks facilitated or hindered their teaching of mathematics and instructional changes as advocated in Shanghai's curriculum reform, and the role the textbooks played in different processes (e.g., preparation for the lesson, activities during instruction, and reflection after instruction) of their teaching.

A pilot study was conducted in May, 2020, with four mathematics teachers from two non-sample secondary schools in Shanghai completing the questionnaire and two of them being further interviewed. The results were overall positive, and the feedback was used for refining the research instruments. The final questionnaire has a Cronbach's $\alpha$ of 0.98 , indicating high reliability.

\subsection{Data collection and analysis}

The questionnaire survey took place in June 2020. As described above, the questionnaire was distributed to all 137 mathematics teachers in the 13 schools, and collected back from 133 of them-a response rate of $97.1 \%$.

Following the questionnaire survey, 26 teachers from the 13 schools were invited to participate in the interview, and eventually 24 of them were interviewed face-to-face (17 teachers) or online (7 teachers), with an average duration of $23.0 \mathrm{~min}$. The interviewees had different lengths of teaching experience with an average of 13.9 years. All interviews except one were audio-recorded, and one was recorded in written notes.

The interview data in audio records were first transcribed into text in Chinese and then, together with the written notes, translated into English. For anonymity, T1 to T24 were used to refer to the 24 interviewees for data analysis. Two researchers coded the data collected from the OEQs and the interview. In general, the procedure was straightforward with high consistency. In a few cases, a third researcher was invited to decide codes for more complex situations to ensure reliability.

\section{Results and discussion}

Below we report first the overall results on how mathematics textbooks facilitated (or hindered) teachers' teaching, followed by the results in terms of different groups of teachers, and finally the results in terms of different kinds of textbooks, that is, student books, teacher manuals, and exercise books.

\subsection{How textbooks facilitated teachers' teaching}

As described earlier, the study examined how textbooks facilitate Shanghai teachers' teaching by examining five different dimensions, namely, comprehension, transformation, instruction, evaluation, and reflection.

\subsubsection{Comprehension}

Table 3 presents the results concerning how the textbooks (including the student book, teacher manual, and exercise book) facilitated teachers' teaching in 'comprehension' in nine aspects.

The results clearly show that teachers overall had a highly positive view in all nine aspects. More specifically, 
Table 3 How textbooks facilitated teachers' comprehension $(N=133)$

\begin{tabular}{|c|c|c|c|c|c|c|}
\hline $\begin{array}{l}\text { Student } \\
\text { book }\end{array}$ & & & & & $\mathrm{Ov}$ & \\
\hline SD & $M$ & SD & $M$ & SD & 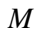 & SD \\
\hline
\end{tabular}

Of ideas within and outside mathematics

Understanding of internal and external connections of mathematics

$\begin{array}{llllllll}3.54 & 0.52 & 3.66 & 0.49 & 3.44^{\mathrm{a}} & 0.56 & 3.55^{\mathrm{a}} & 0.46\end{array}$

Of mathematical content knowledge

Understanding of mathematical concepts

Understanding of mathematical formulas and theorems

$\begin{array}{llllllll}3.62 & 0.49 & 3.73 & 0.46 & 3.50 & 0.52 & 3.62 & 0.43\end{array}$

Understanding of mathematics thinking and methods

$\begin{array}{lllllllll}3.62 & 0.49 & 3.70 & 0.48 & 3.50 & 0.56 & 3.61 & 0.45\end{array}$

Understanding of different representations of mathematics

$\begin{array}{lllllllll}3.41 & 0.58 & 3.62 & 0.53 & 3.35 & 0.60 & 3.46 & 0.51\end{array}$

Of purposes

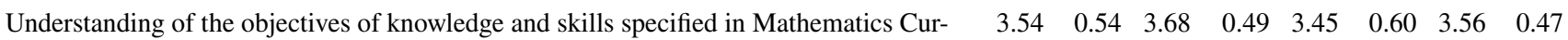
riculum Standards

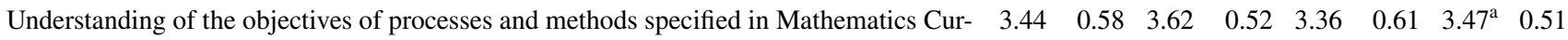
riculum Standards

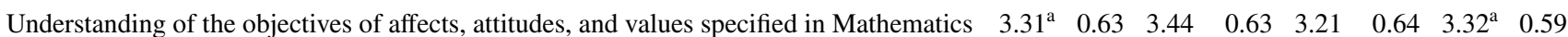
Curriculum Standards

Of students' characteristics

Knowing students' characteristics

$\begin{array}{llllllll}3.14^{\mathrm{a}} & 0.73 & 3.20 & 0.71 & 3.19 & 0.75 & 3.18^{\mathrm{a}} & 0.68\end{array}$

${ }^{\mathrm{a}} N=132$

${ }^{\mathrm{b}} N=131$

${ }^{\mathrm{c}} N=130$

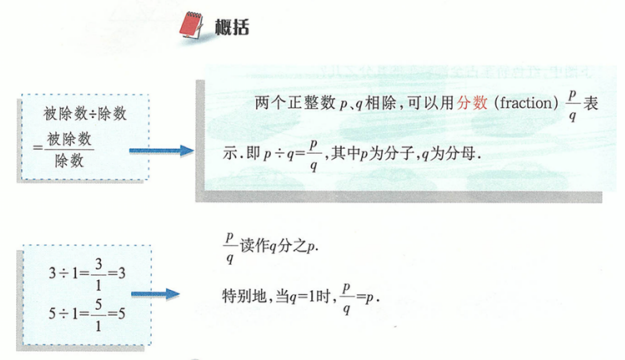

The definition of 'fractions' is given as the division of two

Student book (Grade 6, Semester 1), p. 29

整数和分数统称为有理数(rational number).

$$
\text { 有理数 }\left\{\begin{array}{l}
\text { 整数 }\left\{\begin{array}{l}
\text { 焉整数 } \\
\text { 负整数 }
\end{array}\right. \\
\text { 分数 }\left\{\begin{array}{l}
\text { 焉分数 } \\
\text { 数 }
\end{array}\right.
\end{array}\right.
$$

如果我们把整数看成是分母为 1 的分 数,那么在这个意义下,所有的有理数都是 分数.

Student book (Grade 6, Semester 2), p. 3 positive integers, which is in fact the definition of positive fractions.

Here, integers and fractions are collectively defined as 'rational numbers', and the figure below shows that 'integers' include positive integers, negative integers and $\leftarrow$ zero; 'fractions' include positive fractions and negative fractions.

The text box below the figure also explains that if integers can be viewed as fractions with denominator 1 , all rational numbers are fractions.

Fig. 1 Definitions of 'fraction' and 'rational number' given in the grade 6 student books (Shanghai School Curriculum Reform Committee, 2019a, 2019b); English added 
according to the responses, textbooks were most helpful in their 'understanding of mathematical concepts' $(M=3.62)$ and 'understanding of formulas and theorems' $(M=3.61)$, followed by 'understanding of the objectives of knowledge and skills specified in Mathematics Curriculum Standards' $(M=3.56)$, 'understanding of internal and external connections of mathematics' $(M=3.55)$, 'understanding of the objectives of processes and methods as specified in Mathematics Curriculum Standards' $(M=3.47)$, 'understanding of mathematics thinking and methods' $(M=3.46)$, 'understanding of different representations of mathematics' $(M=3.46)$, 'understanding of the objectives of affects, attitudes, and values specified in Mathematics Curriculum Standards' $(M=3.32)$, and finally 'knowing students' characteristics' $(M=3.18)$.

In the responses from 111 teachers to OEQ 1 in the questionnaire, $82(73.9 \%)$ teachers confirmed that textbooks had facilitated their teaching in their recent lessons and 78 (95.1\%) also provided concrete examples. Among the examples, 62 (79.5\%) were about facilitating teachers' 'comprehension', with 24 teachers showing how textbooks helped them in understanding mathematics concepts and 38 teachers in understanding mathematical formulas and theorems.

During the interviews, nine teachers explained how textbooks helped them teach mathematical concepts. For example, T9 pointed out that the formal and standard expressions of mathematics concepts given in student books offered essential help in her teaching. Another example was offered by T24, who used the textbook's treatment of 'expanding number systems' as an example and elaborated that in the first semester of grade 6, the definition of fractions was introduced; later, the concept of rational numbers was introduced in the second semester of grade 6 , in which was written in the textbook: "integers and fractions are collectively called rational numbers"; and it specified that this definition also included negative fractions. T24 elaborated: "Nowadays the spiral-approach development of students' knowledge is emphasized, especially how to teach certain knowledge to students at different ages, [...] and I think this is welldesigned, the spiral-approach development of knowledge is beneficial to students."

Figure 1 shows the two textbook pages mentioned above.

It appears clear that the reason teachers reported that textbooks offered the least help in facilitating their 'knowing students' characteristics' was related to the fact that textbooks were for general and potential students but teachers' teaching was for specific and real students. This was revealed during the interview with $\mathrm{T} 2$, who explained that textbooks could not tell his students' prior knowledge, and when teaching the method of solving linear equation in one variable (grade 6), he found that textbooks assumed all students would have learned 'the properties of an equation', which was not true in his class.

\subsubsection{Transformation}

Table 4 shows teachers' responses concerning how textbooks facilitated their 'transformation' as defined earlier.

Again, the teachers overall had a highly positive view in all the aspects. According to the responses, textbooks helped most in facilitating their 'setting learning objectives for each lesson' $(M=3.57)$ and 'designing the overall structure of teaching contents' $(M=3.57)$, followed by 'selections of examples in classroom teaching' $(M=3.53)$, 'explanations of contents in classroom teaching' $(M=3.52)$, 'penetration of mathematics thinking and methods in classroom teaching' $(M=3.48)$, 'selections of representations in classroom teaching' ( $M=3.47)$, and finally 'selections of teaching modes in classroom teaching' $(M=3.42)$ and 'organizing activities in classroom teaching' $(M=3.42)$.

The fact that the teachers regarded textbooks highly, especially teacher manuals $(M=3.71)$, as a facilitator for their setting of lesson objectives is not surprising, since the textbooks in Shanghai provided clear messages about learning objectives, and in the case of teacher manuals, explaining general objectives of learning mathematics and the learning objectives of a semester, of a chapter, and finally of a lesson. This was also confirmed during the interviews, in which six teachers reported that textbooks supported their setting of lesson objectives, and T5 particularly illustrated that at the beginning of lesson planning, he would analyze the learning objectives of a lesson provided in the teacher manual.

In response to OEQ 1, five teachers used the chapter 'Quadrilaterals' in the student book as an example to explain how textbooks facilitated their designing the overall structure of content of teaching, and they indicated that the sequence and structure of the chapter were reasonable, as the parallelogram was introduced first and the definitions of rectangle and rhombus were then introduced based on the parallelogram. In the interview, 14 teachers indicated that textbooks helped them clarify the structure and sequencing of mathematics knowledge being taught. Textbooks' facilitation in 'selections of examples in classroom teaching' ( $M=3.53)$ was also confirmed by 15 teachers in their answers to OEQ 1, and they expressed that examples in the textbooks were classic. One teacher pointed out that an example about the midsegment of a trapezoid contained a basic figure but had multiple solutions, which helped his implementing of 'teaching with variation', an idea currently widely advocated in the curriculum reform in China $(\mathrm{Gu}$ et al., 2004).

'Permeation of mathematical thinking and methods in classroom teaching' ( $M=3.48)$ received an intermediatelevel rating among items in transformation. In responses to OEQ 1, however, 19 teachers offered examples to illustrate how textbooks helped them in this aspect. For example, a teacher noted that textbooks helped promote the permeation 
Table 4 How textbooks facilitated teachers' transformation $(N=133)$

\begin{tabular}{|c|c|c|c|c|c|c|c|c|c|}
\hline & \multicolumn{2}{|c|}{ Student book } & \multicolumn{2}{|c|}{ Teacher manual } & & \multicolumn{2}{|c|}{ Exercise book } & \multicolumn{2}{|c|}{ Overall } \\
\hline & $M$ & SD & $M$ & SD & & $M$ & SD & $M$ & SD \\
\hline \multicolumn{10}{|l|}{ Preparation: classification of teaching purposes } \\
\hline Setting learning objectives for each lesson & 3.54 & 0.53 & 3.71 & 0.47 & 3.47 & & 0.61 & 3.57 & 0.46 \\
\hline \multicolumn{10}{|l|}{ Preparation: structuring and sequencing } \\
\hline Designing the overall structure of teaching contents & 3.56 & 0.54 & 3.67 & 0.49 & 3.47 & & 0.57 & 3.57 & 0.47 \\
\hline \multicolumn{10}{|l|}{ Representation: examples } \\
\hline Selections of examples in classroom teaching & 3.54 & 0.54 & 3.59 & 0.54 & 3.47 & & 0.63 & 3.53 & 0.52 \\
\hline \multicolumn{10}{|l|}{ Representation: explanations } \\
\hline Explanations of contents in classroom teaching & $3.48^{\mathrm{a}}$ & 0.53 & 3.66 & 0.49 & 3.42 & & 0.54 & $3.52^{\mathrm{a}}$ & 0.46 \\
\hline \multicolumn{10}{|l|}{ Representation } \\
\hline Selections of representations in classroom teaching & $3.47^{\mathrm{b}}$ & 0.52 & $3.56^{\mathrm{a}}$ & 0.51 & $3.39^{\mathrm{a}}$ & & 0.57 & $3.47^{\mathrm{b}}$ & 0.47 \\
\hline \multicolumn{10}{|l|}{ Other representation } \\
\hline $\begin{array}{l}\text { Penetration of mathematics thinking and methods in } \\
\text { classroom teaching }\end{array}$ & $3.48^{\mathrm{a}}$ & 0.55 & 3.60 & 0.54 & 3.33 & & 0.61 & $3.48^{\mathrm{a}}$ & 0.48 \\
\hline \multicolumn{10}{|l|}{ Selection: modes of teaching } \\
\hline Selections of teaching modes in classroom teaching & $3.41^{\mathrm{a}}$ & 0.59 & 3.50 & 0.56 & 3.35 & & 0.63 & $3.42^{\mathrm{a}}$ & 0.52 \\
\hline \multicolumn{10}{|l|}{ Selection: organizing and managing } \\
\hline Organizing activities in classroom teaching & $3.44^{\mathrm{a}}$ & 0.60 & 3.47 & 0.56 & 3.35 & & 0.58 & $3.42^{\mathrm{a}}$ & 0.52 \\
\hline
\end{tabular}

${ }^{\mathrm{a}} N=132$

${ }^{\mathrm{b}} N=131$

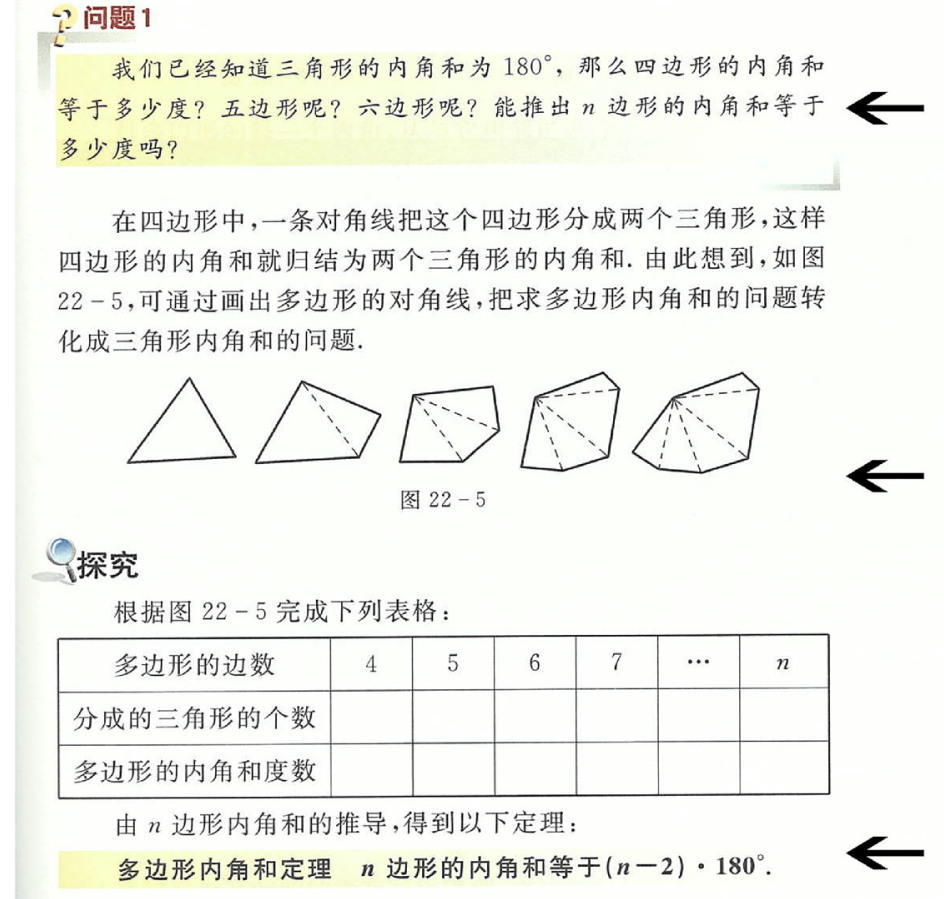

First, given that the sum of all interior angles of a triangle is $180^{\circ}$, a number of questions are posed in the textbook, asking students to calculate the sum of all interior angles for a quadrilateral, a pentagon, a hexagon, and then for an n-sided polygon.

Next, using the diagonals, it is shown that the polygons can be divided into several triangles, so that the sum of all interior angles of a polygon is related to that of a triangle. An inquiry task is also designed to let students explore that, for polygons with different numbers of sides, how many triangles can be obtained by drawing diagonals, and thus calculating the sums of all interior angles.

Following on from the previous process, the theorem of the sum of all interior angles of a polygon is deduced.

Fig. 2 Theorem of the sum of all interior angles of a polygon (Shanghai School Curriculum Reform Committee, 2019c, p. 67); English added 
of the mathematical thinking of 'generalization' in the introduction of the theorem of the sum of all interior angles of a polygon, as the textbook started from the case of a triangle, quadrilateral, pentagon, and hexagon, then generalized it to an n-sided polygon (see Fig. 2).

Teachers' relatively low evaluations of 'selections of teaching modes' and 'selections of organizing activities' appear to be related to the fact that the textbooks in general do not offer specific instructions about teaching modes and organizing activities, except in the student books, which contain a section on 'Inquiry activities', as advocated in the curriculum reform, which one teacher answering OEQ 1 and one teacher in the interview said was helpful in their teaching.

\subsubsection{Instruction}

Table 5 presents the results about how the textbooks facilitated classroom 'instruction' as discussed above.

Again, the teachers overall had a positive response in all the aspects. The results show that the textbooks helped most in teachers' 'effective questioning' $(M=3.40)$, followed by 'helping students avoid common misconceptions' $(M=3.39)$, 'implementing ideas of mathematics curriculum reform' $(M=3.37)$, 'effective interactions with students' $(M=3.30)$, 'stimulating students' learning motivations' $(M=3.27)$, and finally 'helping students overcome learning difficulties' ( $M=3.25)$ in their classroom teaching.

We think the reason that Shanghai teachers gave a higher rating to 'effective questioning' in this dimension is more or less related to the design of student books, which contain sections of 'Questions' with one or more questions. In fact, one teacher indicated that the questions in the section provided in the student books were helpful when she introduced the concept of irrational numbers.

It is especially worth noting that overall, the teachers reported that textbooks facilitated their implementing ideas of curriculum reform $(M=3.37)$, which is likely due to the fact that the development of textbooks in Shanghai is required to follow the unified curriculum standards. During the interview, 17 teachers described how textbooks assisted them in implementing curriculum reform, such as using innovative teaching modes and emphasizing mathematics thinking and methods. For instance, T12 was inspired by the textbooks to change her teaching methods. She said: "Textbooks (helped me) replace traditional indoctrination by inquiry teaching. Currently, in most cases, textbooks offer a problem-driven context in teaching, that is, to pose a question in class [...]. It contains a main question, and we (teachers) will design some related questions based on the main one in the textbooks, replacing the traditional indoctrination way of teaching. In class, we will give pupils some time to discuss in order to facilitate their understanding of the concepts."

\subsubsection{Evaluation and reflection}

Three items in the questionnaire concern how textbooks facilitate teachers' 'evaluation' and 'reflection' concerning their teaching. As shown in Table 6, the results suggest that the teachers also had an overall positive view about the role of textbooks in the related aspects.

More specifically, textbooks played a more facilitating role in their formative assessments $(M=3.30)$ than summative assessments $(M=3.27)$, and to a greater degree facilitated their reflection about teaching $(M=3.34)$.

Table 5 How textbooks facilitated teachers' instruction $(N=133)$

\begin{tabular}{|c|c|c|c|c|c|c|c|c|}
\hline & \multicolumn{2}{|c|}{ Student book } & \multicolumn{2}{|c|}{$\begin{array}{l}\text { Teacher } \\
\text { manual }\end{array}$} & \multicolumn{2}{|c|}{ Exercise book } & \multicolumn{2}{|c|}{ Overall } \\
\hline & $M$ & SD & $M$ & SD & $M$ & SD & $M$ & SD \\
\hline \multicolumn{9}{|l|}{ Adaptation and tailoring to student characteristics: students' motivations } \\
\hline Stimulating students' learning motivations in classroom teaching & $3.26^{\mathrm{a}}$ & 0.63 & 3.32 & 0.62 & 3.21 & 0.63 & $3.27^{\mathrm{a}}$ & 0.58 \\
\hline \multicolumn{9}{|l|}{ Adaptation and tailoring to student characteristics: difficulties } \\
\hline Helping students overcome learning difficulties in classroom teaching & 3.28 & 0.67 & 3.31 & 0.63 & 3.17 & 0.66 & 3.25 & 0.60 \\
\hline \multicolumn{9}{|l|}{ Adaptation and tailoring to student characteristics: misconception } \\
\hline Helping students avoid common misconceptions in classroom teaching & 3.37 & 0.61 & 3.47 & 0.62 & 3.32 & 0.61 & 3.39 & 0.55 \\
\hline \multicolumn{9}{|l|}{ Interactions } \\
\hline Effective interactions with students in classroom teaching & $3.30^{\mathrm{a}}$ & 0.61 & 3.35 & 0.62 & 3.23 & 0.57 & $3.30^{\mathrm{a}}$ & 0.56 \\
\hline \multicolumn{9}{|l|}{ Questioning } \\
\hline Effective questioning in classroom teaching & $3.40^{\mathrm{a}}$ & 0.56 & 3.50 & 0.59 & 3.29 & 0.57 & $3.40^{\mathrm{a}}$ & 0.51 \\
\hline \multicolumn{9}{|l|}{ Instructional practices advocated in curriculum reform } \\
\hline Implementing ideas of mathematics curriculum reform in my teaching & $3.39^{\mathrm{a}}$ & 0.57 & 3.44 & 0.60 & 3.26 & 0.61 & $3.37^{\mathrm{a}}$ & 0.54 \\
\hline
\end{tabular}

${ }^{\mathrm{a}} N=132$ 
Table 6 How textbooks facilitated teachers' evaluation and refection $(N=133)$

\begin{tabular}{|c|c|c|c|c|c|c|c|c|}
\hline & \multicolumn{2}{|c|}{ Student book } & \multicolumn{2}{|c|}{ Teacher manual } & \multicolumn{2}{|c|}{ Exercise book } & \multicolumn{2}{|c|}{ Overall } \\
\hline & $M$ & SD & $M$ & SD & $M$ & SD & $M$ & SD \\
\hline \multicolumn{9}{|l|}{ Evaluation } \\
\hline \multicolumn{9}{|c|}{ Checking for student understanding during interactive teaching } \\
\hline Formative assessments & $3.29^{\mathrm{a}}$ & 0.65 & 3.31 & 0.67 & 3.26 & 0.68 & $3.30^{\mathrm{a}}$ & 0.60 \\
\hline \multicolumn{9}{|c|}{ Testing student understanding at the end of lessons or units } \\
\hline Summative assessments & $3.27^{\mathrm{a}}$ & 0.65 & 3.32 & 0.70 & 3.19 & 0.69 & $3.27^{\mathrm{a}}$ & 0.62 \\
\hline \multicolumn{9}{|l|}{ Reflection } \\
\hline \multicolumn{9}{|c|}{ Critically analyzing one's own instructional process } \\
\hline Teaching reflections & $3.30^{\mathrm{c}}$ & 0.62 & $3.38^{\mathrm{b}}$ & 0.63 & $3.29^{\mathrm{b}}$ & 0.62 & $3.34^{\mathrm{c}}$ & 0.55 \\
\hline
\end{tabular}

Regarding the moderately positive role textbooks played in facilitating their 'formative assessment', it should be noted that while most Shanghai teachers assign mathematics tasks from textbooks (including both student books and exercise books) during and/or after lessons, they also use other resources for formative assessment. During the interview, T3 said that mathematics tasks from student books and exercise books were too easy for her students, so she would add more mathematics problems from other resources.

The fact that textbooks played a less positive role in facilitating teachers' 'summative assessments' was unexpected to us, but the interview did reveal why this was the case. As T15 pointed out, problems from student books and exercise books were not challenging enough for his students, and even if a student did well in solving textbook problems, he/she might not do well in Shanghai's High School Entrance Examination or 'ZhongKao', a high-stakes test in Chinese test culture. Therefore, teachers would have to use other resources for summative assessments. In this case, textbooks played a hindering rather than facilitative role in teachers' teaching.

In terms of teaching reflection, 16 interviewed teachers viewed textbooks as facilitators. Thirteen of them mentioned that textbooks, especially teacher manuals, helped them reflect on the foci and difficulties of teaching and teaching objectives.

We also compared teachers' responses to the five dimensions by calculating the means of those teacher's responses to the items in each dimension, and found that overall, textbooks played the largest facilitation role in 'transformation' $(M=3.50)$, followed by 'comprehension' $(M=3.47)$, 'reflection' $(M=3.34)$, 'instruction' $(M=3.33)$ and 'evaluation' $(M=3.28)$. In other words, the textbooks were most helpful to teachers in the stage of preparation for teaching (i.e., comprehension and transformation) and in comparison, and least helpful in evaluation, for the reasons discussed earlier.
Finally, in all the responses to the OEQs in the questionnaire, $78(58.6 \%)$ of the 133 Shanghai teachers gave examples of textbooks facilitating their teaching in one of their recent lessons (some of the examples are shown above), while only $34(25.6 \%)$ teachers reported that textbooks failed to facilitate or hindered their teaching in recent lessons. Consistent with what was reported earlier, the results also suggest that textbooks were overall more of a facilitator than a barrier in the teachers' teaching.

\subsection{Different teachers' responses on how textbooks facilitated their teaching}

To further detect if there exist differences between different teachers concerning the role of textbooks in teaching, we compared the responses of teachers by classifying them into different groups, first in terms of school characteristics based on student performance levels (high-performing vs. ordinary), school locations (urban vs. suburban), and funding sources (public vs. private), and then in terms of teacher characteristics based on teaching experiences (10 years or less; $10-20$ years; more than 20 years) and educational backgrounds. $^{5}$

Table 7 depicts the results from chi-square tests for the purpose of investigating whether the above factors of teachers bear an influence on their behaviors and perceptions concerning how textbooks facilitated their teaching.

As shown in the table, significant differences were found between teachers in high-performing schools and those in the ordinary schools with regard to the role that textbooks played in 'selecting teaching modes' (exercise books, $\left.\chi^{2}=6.164, p<0.05\right)$, 'stimulating students' learning

\footnotetext{
5 Since there was only one teacher whose highest education qualification was a diploma, we combined this teacher with other teachers with bachelor's degrees to compare with teachers who held master's degrees.
} 


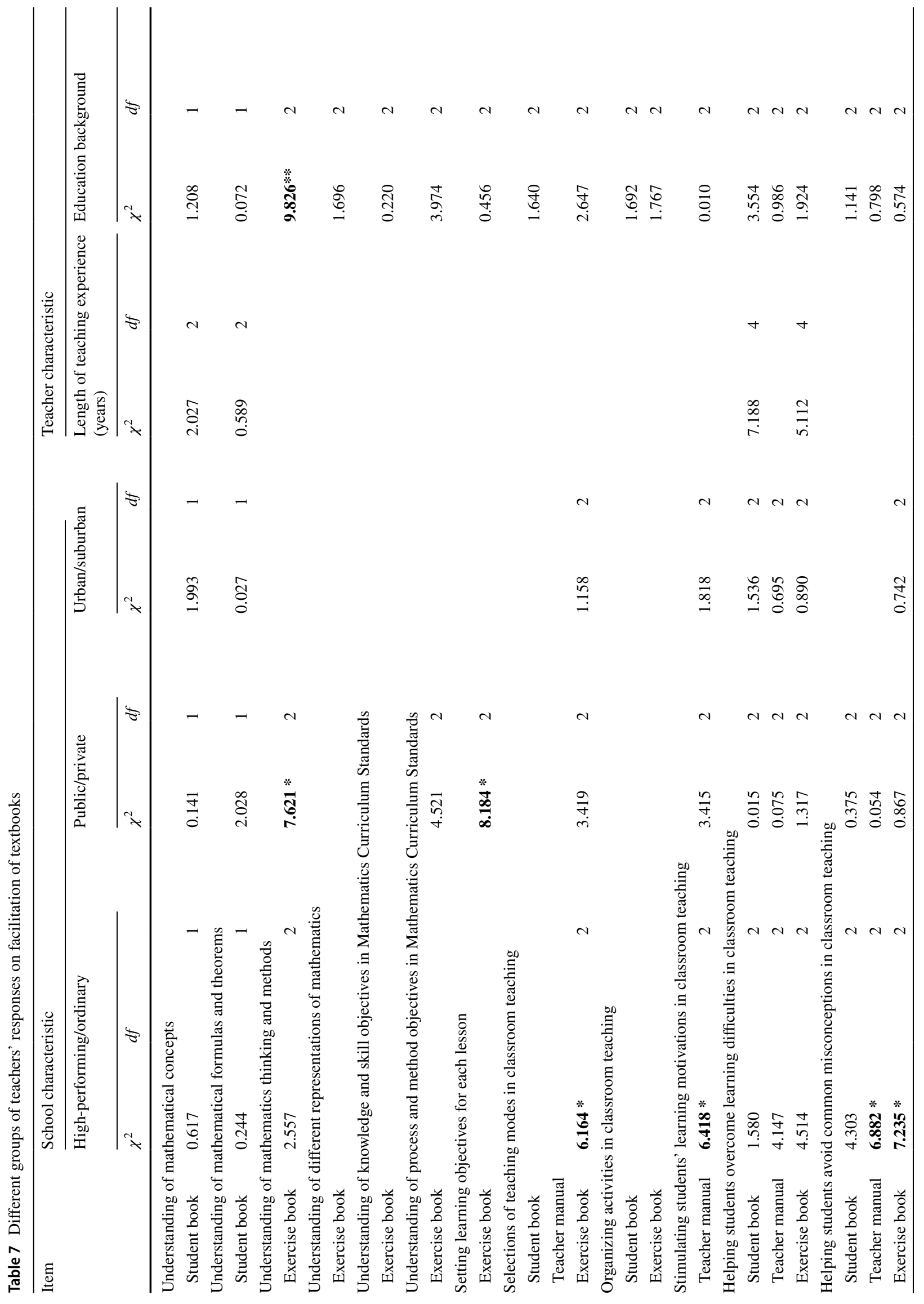




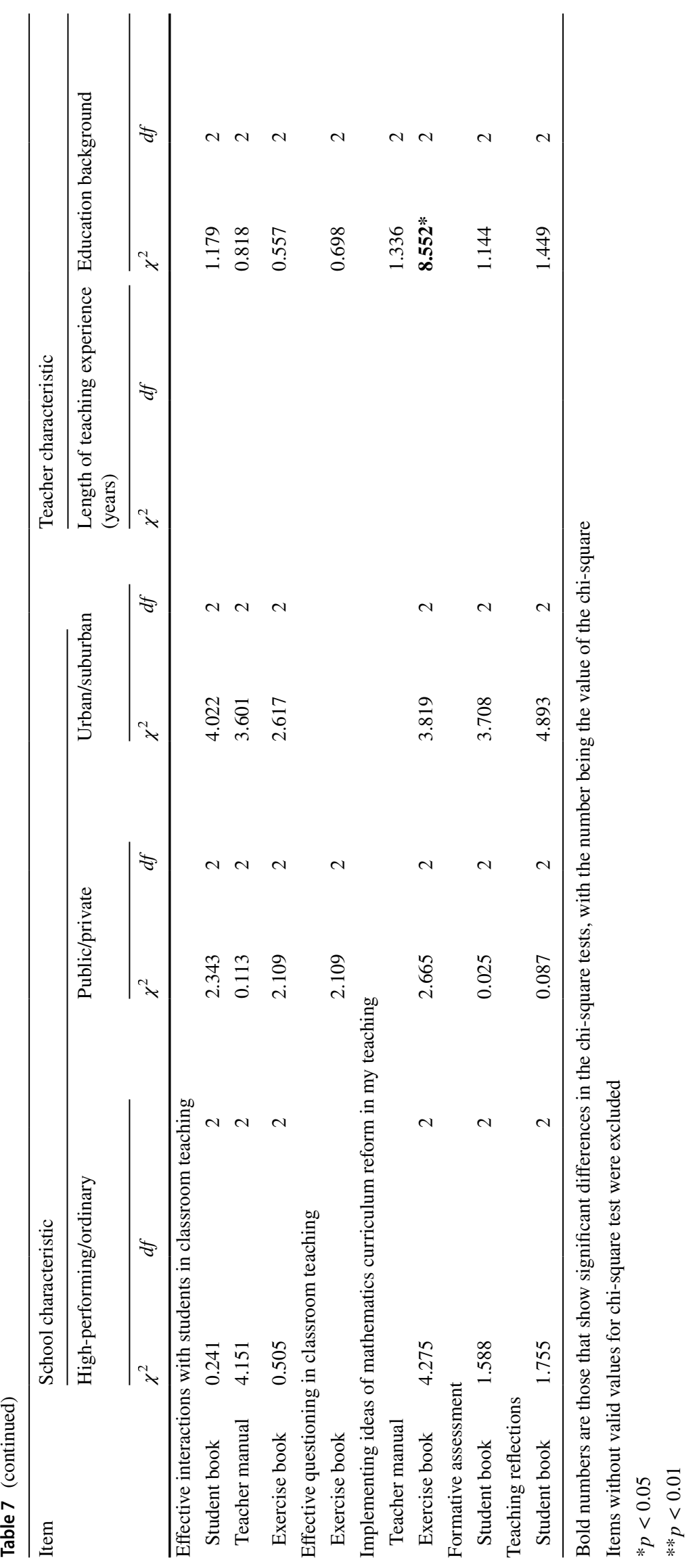


motivations' (teacher manuals, $\chi^{2}=6.418, p<0.05$ ), and 'helping students avoid common misconceptions' (teacher manuals, $\chi^{2}=6.882, p<0.05$; exercise books, $\left.\chi^{2}=7.235, p<0.05\right)$. Moreover, in all the above cases, textbooks played a significantly more facilitating role in teachers' teaching in ordinary schools, which appears understandable since teachers in high-performing schools are likely to depend less on textbooks to suit the need and level of students who are generally more motivated and have fewer misconceptions. This aspect was also confirmed in the interviews. For example, T13 and T14 from high-performing schools explained that the mathematical knowledge presented in student books and mathematics problems in exercise books were not challenging enough for their students; as T14 said, "Shanghai textbooks are very useful for [students in] ordinary schools. But the level of prior knowledge of students in our school is higher than that of students in ordinary schools, so the applicability of Shanghai textbooks in our school is not high."

Since public schools and private schools have different funding sources, along with different management systems, school policies, and goals, we were interested in determining whether textbooks played different roles in teachers' teaching in these two types of schools. The statistical results showed no significant differences between them in all the factors, except that exercise books played a significantly more facilitating role in public schools in teachers' 'understanding of mathematics thinking and methods' $\left(\chi^{2}=7.621, p<0.05\right)$ and 'setting learning objectives for each lesson' $\left(\chi^{2}=8.184, p<0.05\right)$. As five teachers from different private schools explained during the interview, the reason was that in private schools, students generally have better academic backgrounds, and moreover, teachers have more flexibility in teaching and hence depend less on textbooks.

Likewise, there existed significant differences between the teachers with a diploma or bachelor's degree and those with master's degrees in using exercise books for their 'understanding of mathematics thinking and methods' $\left(\chi^{2}=9.826, p<0.01\right)$ and 'implementing ideas of mathematics curriculum reform' $\left(\chi^{2}=8.552, p<0.05\right)$. For both items, teachers with master's degrees reported that textbooks played a significantly less facilitating role. This result was not surprising, since teachers with higher degrees usually received more professional training and would rely less on instructional resources when teaching.

No significant differences were found between teachers in terms of school location. The reason could be related to the fact that overall, there were no substantial differences between urban schools and suburban schools in Shanghai.

It is interesting and unexpected to us that no significant differences were found between teachers with different years of teaching experience. It appears that textbooks played largely a similar role in Shanghai teachers' teaching no matter how many years they had taught, and we think this fact is likely related to the tradition and culture of teaching and teacher professional development, especially the functions of Teaching Research Groups in schools, in Shanghai and, we conjecture, even in China.

To summarize, compared with teacher characteristics, school characteristics had a greater influence on the extent to which textbooks facilitated teachers' teaching. Moreover, significant differences between different teachers were found in using all kinds of textbooks except student books, suggesting there exist differences between the roles of different kinds of textbooks, which will be further discussed in the next section.

\subsection{Teachers' responses on the facilitation role of different kinds of textbooks}

As described earlier, the term 'textbooks' is broadly used in this study to include student books, teacher manuals, and exercise books. Accordingly, in the questionnaire, each item that uses

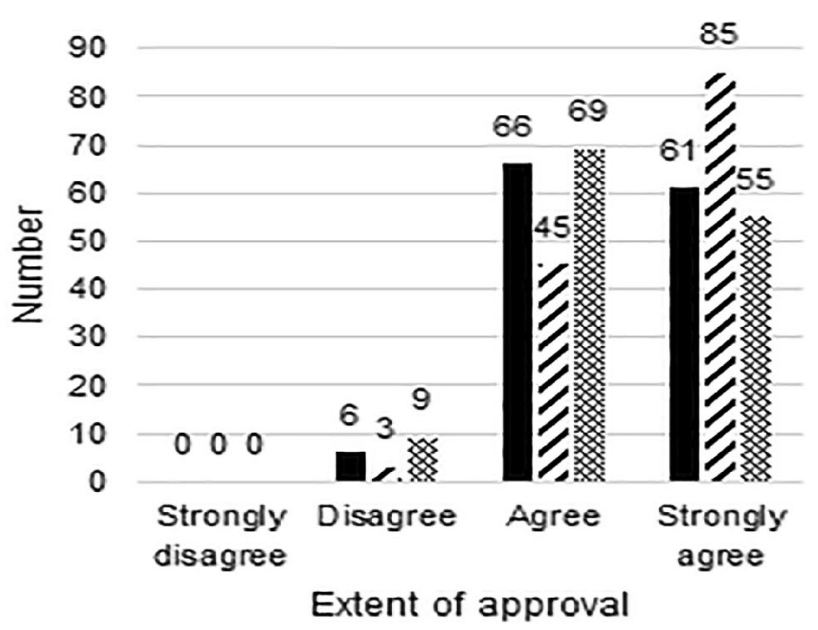

\section{Student book - Teacher manual Exercise book}

Fig. 3 Distribution of the numbers of teachers with different evaluations concerning mathematics thinking and methods 
the general term 'textbooks' contained three further sub-items specifying student book, teacher manual, and exercise book.

To reveal whether there are significant differences in the roles of these three kinds of textbooks in facilitating teachers' teaching, we used the Friedman test, and the results showed that overall, there were significant differences in the roles of student books, teacher manuals, and exercise books in all the items $(p<0.05)$ except in facilitating teachers' 'knowing students' prior knowledge' and 'formative assessment'. Among these factors, the most significant differences existed in facilitating teachers' 'understanding of mathematics thinking and methods' $\left(\chi^{2}=42.133, p<0.001\right)$, as shown in Fig. 3 .

To further examine if there were significant differences between any two of the three kinds of textbooks, Wilcoxon signed-rank tests were conducted, ${ }^{6}$ and the results showed that teacher manuals played a significantly more facilitating role in teachers' 'understanding of mathematics thinking and methods' than student books $(Z=4.700, p<0.001)$ and exercise books $(Z=5.549, p<0.001)$, while there were no significant differences between student books and exercise books.

The results of Wilcoxon signed-rank tests also revealed that teachers' evaluation of the role of teacher manuals in each item was significantly higher than that of exercise books, except in facilitating teachers' 'knowing students' prior knowledge' and 'formative assessment'. Moreover, teachers' evaluations of teacher manuals in all but six items were significantly higher than that of student books $(p<0.05)$, while teachers' evaluations of the role of exercise books were significantly lower than that of student books in 12 of the items $(p<0.05)^{7}$.

In other words, in comparison, teacher manuals to a large degree played a more important role than student books, which to a lesser degree played a more important role than exercise books in facilitating teachers' teaching. This result is not surprising, as previous research revealed that Chinese teacher manuals were designed to "help teachers achieve a thorough understanding of student text(books) mathematically and pedagogically" (Li, 2004 , p. 262). In fact, this was also confirmed during the interviews; for example, T23 said: "When I taught the chapter on parallel lines, one of the questions I liked very much was that for a picture with many lines including straight lines, rays, and line segments, $[\ldots]$ the teacher manual suggested teachers not involve too many technical issues [here], because this is not actually the essential content [objective] of this chapter". As for exercise books, they are designed mainly to provide students with

\footnotetext{
6 For detailed statistical test results, see Online Resource 3.

7 For detailed statistical test results, see Online Resource 3.
}

more exercise questions with or without teachers' guidance, and naturally they played an overall less important role than student textbooks for Shanghai teachers' teaching.

\section{Summary and conclusions}

This study had the aim of examining whether and how mathematics textbooks facilitate or hinder teachers' teaching in Shanghai educational settings. The data were collected from a stratified random sample of 133 mathematics teachers in 13 secondary schools through a questionnaire and follow-up interviews. According to the data and the analysis presented above, we think the following conclusions can be drawn.

First, with regard to the overarching research question, the study found that to a large extent, textbooks play a facilitating role in Shanghai mathematics teachers' teaching and instructional change. In fact, as shown in Tables 3, 4, 5, 6, teachers had consistently positive views on the facilitating role of all three kinds of textbooks (student books, teacher manuals, and exercise books) and items of all the five dimensions (processes) of teachers' pedagogical reasoning and actions-comprehension, transformation, instruction, evaluation, and reflection. The interview data also revealed that the textbooks were consistently highly regarded and used by Shanghai teachers as facilitators rather than barriers for their instructional practice.

As mentioned earlier, researchers have looked into textbooks to explore reasons behind the outstanding performance of Shanghai students in the PISA tests. Given the finding that textbooks to a large degree play a facilitation role in Shanghai teachers' teaching of mathematics, it seems reasonable to conjecture that such a facilitating role of textbooks in Shanghai may well have contributed to teachers' better teaching and thus students' better learning outcomes, as shown in the PISA tests. Nevertheless, more research specifically addressing the issue is needed to confirm this relationship.

Second, the facilitation of textbooks for Shanghai teachers' teaching is most evident in the processes of transformation and comprehension and least evident in evaluation (including both summative and formative assessment). In other words, the textbooks are most helpful to the teachers in their preparation for teaching, and in comparison, least helpful in evaluation.

Furthermore, in the preparation stage of teaching, it was found that textbooks played a highly facilitating role in teachers' understanding of mathematical content, including mathematics concepts, formulae, and theorems. The result is consistent with the findings of some previous studies (e.g., Van Steenbrugge et al., 2018) that textbooks helped teachers understand central ideas of mathematics for their teaching. 
With regard to evaluation, according to the results from the interview data and previous literature (e.g., Ulusoy \& Incikabi, 2020), we think that textbook developers need to design assessment tasks in such a way that they can better meet the needs and levels of different students so as to better facilitate teachers' teaching. In addition, the study revealed that textbooks may play a hindrance role in mathematics teaching, for example, inhibiting students' understanding by using outdated backgrounds, implying that it is important for textbook developers to keep textbooks up to date.

Third, pertaining to the first sub-question, it was found that Shanghai schools' characteristics have a greater influence on the extent to which textbooks play a facilitator role in the teachers' teaching. More specifically, textbooks play a larger facilitation role in teachers' teaching in ordinary schools and public schools. In contrast, the influence of teacher characteristics is much less, and there are virtually no differences between teachers of different genders or with different years of teaching experience when it comes to textbooks' role in their teaching, which we think is probably related to the fact that the Teaching Research Groups within schools in Shanghai play an important role in coordinating teachers' teaching and their professional development in relation to textbook use.

Fourth, pertaining to the second sub-question, the study found that teacher manuals play a larger facilitation role than student books and exercise books in Shanghai teachers' teaching. Moreover, compared with teacher manuals and student books, exercise books play a less facilitating role, mainly due to the overall insufficiency in level of difficulty of mathematics problems provided to students. Given the impact of teacher manuals in facilitating teachers' teaching as found in this study, we think teacher manuals merit more attention in teachers' preservice and inservice training, in textbook research, and in textbook development.

Finally, we wish to remind the readers that this study focused on mathematics education in Shanghai with a particular set of textbooks, which cannot represent the overall situation in China. Moreover, like many other survey studies, the data collected in the study were from participants' self-reporting, which is subjective by nature and has limitations; therefore, the conclusions should be taken with some caution. Further studies, particularly those using different methods (e.g., observation), are needed to better understand how textbooks play a role in teachers' teaching in other parts of China and, more generally, other countries with different cultural, social, and school contexts; by doing so, we can deepen our understanding of what and how textbooks can better support teachers' teaching practices in different contexts and hence improve the quality of mathematics teaching and learning.
Supplementary Information The online version contains supplementary material available at https://doi.org/10.1007/s11858-021-01306-6.

Acknowledgements We would like to thank Fenghua Zhang (Sofia), Lingzhu Li, Xiaoqi Sun, and the four teachers who participated in the pilot test for their assistance. The study was jointly supported by two research grants by East China Normal University, one from its 'Happy Flowers' Strategic Research Fund (Award No: 2019ECNU-XF2H004) and the other from the Asian Centre for Mathematics Education (Award No: 92900-120215-10514).

\section{References}

Boylan, M., Maxwell, B., Wolstenholme, C., Jay, T., \& Demack, S. (2018). The mathematics teacher exchange and 'mastery' in England: The evidence for the efficacy of component practices. Education Sciences, 8(4), 202.

Boylan, M., Wolstenholme, C., Demack, S., Maxwell, B., Jay, T., Adams, G., \& Reaney, S. (2019). Mathematics teacher exchange: China-England: Technical report and supplementary data and analysis. Sheffield Hallam University.

Brown, M. W. (2009). The teacher-tool relationship: Theorizing the design and use of curriculum materials. In J. T. Remillard, B. A. Herbel-Eisenmann, \& G. M. Lloyd (Eds.), Mathematics teachers at work: Connecting curriculum materials and classroom instruction (pp. 17-36). Routledge.

Carnine, D. (1991). Reforming mathematics instruction: The role of curriculum materials. Journal of Behavioral Education, 1(1), 37-57.

China Ministry of Education. (2011). Professional standards for secondary school teachers (Experimental). http://old.moe.gov.cn/ publicfiles/business/htmlfiles/moe/s6127/201112/127830.html. Accessed 17 Feb 2021.

Darling-Hammond, L. (2006). Constructing 21st-century teacher education. Journal of Teacher Education, 57(3), 300-314.

Davis, J. D. (2009). Understanding the influence of two mathematics textbooks on prospective secondary teachers' knowledge. Journal of Mathematics Teacher Education, 12(5), 365-389.

Ding, L., Jones, K., \& Sikko, S. A. (2017). An expert teacher's use of teaching with variation to support a junior mathematics teacher's professional learning. In R. Huang \& Y. Li (Eds.), Teaching and learning mathematics through variation (pp. 241-246). Sense Publishers.

Ding, M., Li, Y., Li, X., \& Gu, J. (2013). Knowing and understanding instructional mathematics content through intensive studies of textbooks. In Y. Li \& R. Huang (Eds.), How Chinese teach mathematics and improve teaching (pp. 107-209). Routledge.

Divrik, R., Taş, A., \& Pilten, P. (2020). Teachers' views on the problem-solving \& problem-posing tasks in primary school mathematics textbooks. Journal of Curriculum and Teaching, 9(1), 73-85.

Fan, L. (2013). Textbook research as scientific research: Towards a common ground on issues and methods of research on mathematics textbooks. ZDM - the International Journal on Mathematics Education, 45(5), 765-777.

Fan, L., \& Kaeley, G. (2000). The influence of textbooks on teaching strategies: An empirical study. Mid-Western Educational Researcher, 13(4), 2-9.

Fan, L., Chen, J., Zhu, Y., Qiu, X., \& Hu, J. (2004). Textbook use within and beyond mathematics classrooms: A study of $12 \mathrm{sec}-$ ondary schools in Kunming and Fuzhou of China. In L. Fan, N. Y. Wong, J. Cai, \& S. Li (Eds.), How Chinese learn mathematics: Perspectives from Insiders (pp. 228-261). World Scientific. 
Fan, L., Zhu, Y., \& Miao, Z. (2013). Textbook research in mathematics education: Development status and directions. ZDM - the International Journal on Mathematics Education, 45(5), 633-646.

González-Martín, A. S., Nardi, E., \& Biza, I. (2018). From resource to document: Scaffolding content and organising student learning in teachers' documentation work on the teaching of series. Educational Studies in Mathematics, 98(3), 231-252.

Gracin, D. G., \& Matić, L. J. (2019). Same textbook, different points of view: Students and teachers as textbook users. In S. Rezat, L. Fan, M. Hattermann, J. Schumacher, \& H. Wuschke (Eds.), Proceedings of the Third International Conference on Mathematics Textbook Research and Development (pp. 173-178). Paderborn: Universitätsbibliothek Paderborn.

Gravemeijer, K. P. (2014). Transforming mathematics education: The role of textbooks and teachers. In Y. Li, E. A. Silver, \& S. Li (Eds.), Transforming mathematics instruction (pp. 153-172). Springer.

Grouws, D. A., Tarr, J. E., Chávez, Ó., Sears, R., Soria, V. M., \& Taylan, R. D. (2013). Curriculum and implementation effects on high school students' mathematics learning from curricula representing subject-specific and integrated content organizations. Journal for Research in Mathematics Education, 44(2), 416-463.

Gu, L., Huang, R., \& Marton, F. (2004). Teaching with variation: A Chinese way of promoting effective mathematics learning. In L. Fan, N. Y. Wong, J. Cai, \& S. Li (Eds.), How Chinese learn mathematics: Perspectives from insiders (pp. 309-347). World Scientific.

Haggarty, L., \& Pepin, B. (2017). Learning opportunities offered to pupils in England: A cause of concern. In B. Grevholm (Ed.), Mathematics textbooks, their content, use and influences: Research in Nordic and Baltic countries (pp. 117-128). Cappelen Damm Akademisk.

Jamieson-Proctor, R., \& Byrne, C. (2008). Primary teachers' beliefs about the use of mathematics textbooks. In M. Goos, R. Brown, \& K. Makar (Eds.), Proceedings of the 31st Annual Conference of the Mathematics Education: Meeting Research Group of Australasia-MERGA31: Navigating currents and charting directions (pp. 295-302). Brisbane: MERGA.

Johansson, M. (2017). Textbooks as instruments: Three teachers' ways to organize their mathematics lessons. In B. Grevholm (Ed.), Mathematics textbooks, their content, use and influences: Research in Nordic and Baltic countries (pp. 315-340). Cappelen Damm Akademisk.

Kilpatrick, J. (2012). The new math as an international phenomenon. ZDM - the International Journal on Mathematics Education, 44(4), 563-571.

Lepik, M., Grevholm, B., \& Viholainen, A. (2015). Using textbooks in the mathematics classroom-The teachers' view. Nordic Studies in Education, 20(3-4), 129-156.

Li, J. (2004). Thorough understanding of the textbook: A significant feature of Chinese teacher manuals. In L. Fan, N. Y. Wong, J. Cai, \& S. Li (Eds.), How Chinese learn mathematics: Perspectives from insiders (pp. 262-281). World Scientific.

Li, Y., Chen, X., \& Kulm, G. (2009). Mathematics teachers' practices and thinking in lesson plan development: A case of teaching fraction division. ZDM - the International Journal on Mathematics Education, 41(6), 717-731.

Love, E., \& Pimm, D. (1996). "This is so": A text on texts. In A. J. Bishop, K. Clements, C. Keitel, J. Kilpatrick, \& C. Laborde (Eds.), International handbook of mathematics education (Vol. 1, pp. 371-409). Kluwer.

Manouchehri, A., \& Goodman, T. (2000). Implementing mathematics reform: The challenge within. Educational Studies in Mathematics, 42(1), 1-34.

Martin, T. S., Hunt, C. A., Lannin, J., Leonard, W., Jr., Marshall, G. L., \& Wares, A. (2001). How reform secondary mathematics textbooks stack up against NCTM's "Principles and Standards." Mathematics Teacher, 94(7), 540-545. 589.

Matić, L. J., \& Gracin, D. G. (2021). How do teacher guides give support to mathematics teachers? Analysis of a teacher guide and exploration of its use in teachers' practices. Research in Mathematics Education, 23(1), 1-20.

Mengual, E., Gorgorió, N., \& Albarracín, L. (2015). The mathematical textbook as an obstacle in the learning of measure. Quaderni $D i$ Ricerca in Didattica, 25(Supplement 2), 175-183.

Nie, B., Freedman, T., Hwang, S., Wang, N., Moyer, J., \& Cai, J. (2013). An investigation of teachers' intentions and reflections about using Standards-based and traditional textbooks in the classroom. ZDM - the International Journal on Mathematics Education, 45(5), 699-711.

O'Keeffe, L., \& White, B. (2017). A snapshot of the role of the textbook in English secondary mathematics classrooms. International Journal for Mathematics Teaching \& Learning, 18(3), 318-332.

Oates, T. (2014). Why textbooks count. Cambridge Assessment.

OECD. (2013). PISA 2012 result. http://www.oecd.org/pisa/aboutpisa/ pisa-2012-results.htm. Accessed 31 May 2020.

OECD. (2019). PISA 2018 result. http://www.oecd.org/pisa/publicatio ns/pisa-2018-results.htm. Accessed 31 May 2020.

Pepin, B., Gueudet, G., \& Trouche, L. (2013). Investigating textbooks as crucial interfaces between culture, policy and teacher curricular practice: Two contrasted case studies in France and Norway. ZDM - the International Journal on Mathematics Education, 45(5), 685-698.

Prediger, S., Barzel, B., Hußmann, S., \& Leuders, T. (2021). Towards a research base for textbooks as teacher support: The case of engaging students in active knowledge organization in the KOSIMA project. ZDM Mathematics Education. https://doi.org/10.1007/ s11858-021-01245-2

Remillard, J. T. (2005). Examining key concepts in research on teachers' use of mathematics curricula. Review of Educational Research, 75(2), 211-246.

Sellar, S., \& Lingard, B. (2013). Looking East: Shanghai, PISA 2009 and the reconstitution of reference societies in the global education policy field. Comparative Education, 49(4), 464-485.

Shanghai Municipal Education Commission. (2004). Mathematics curriculum standards for primary and secondary schools in Shanghai (experimental). Shanghai Educational Publishing House.

Shanghai School Curriculum Reform Committee. (2019a). Mathematics textbook for compulsory education (Autumn semester, Grade 6). Shanghai Educational Publishing House.

Shanghai School Curriculum Reform Committee. (2019b). Mathematics textbook for compulsory education (Spring semester, Grade 6). Shanghai Educational Publishing House.

Shanghai School Curriculum Reform Committee. (2019c). Mathematics textbook for compulsory education (Spring semester, Grade 8). Shanghai Educational Publishing House.

Shulman, L. S. (1987). Knowledge and teaching: Foundations of the new reform. Harvard Educational Review, 57(1), 1-23.

Sosniak, L. A., \& Perlman, C. L. (1990). Secondary education by the book. Journal of Curriculum Studies, 22(5), 427-442.

Tan, C. (2013). Learning from Shanghai: Lessons on achieving educational success. Springer.

Thompson, D. R., \& Senk, S. L. (2014). The same geometry textbook does not mean the same classroom enactment. ZDM - the International Journal on Mathematics Education, 46(5), 781-795.

Ulusoy, F., \& Incikabi, L. (2020). Middle school teachers' use of compulsory textbooks in instruction of mathematics. International Journal for Mathematics Teaching and Learning, 21(1), 1-18.

Van Steenbrugge, H., Larsson, M., Insulander, E., \& Ryve, A. (2018). Curriculum support for teachers' negotiation of meaning: A collective perspective. In L. Fan, L. Trouche, C. Qi, S. Rezat, \& J. 
Visnovska (Eds.), Research on mathematics textbooks and teachers' resources: Advances and issues (pp. 167-191). Springer.

Viholainen, A., Partanen, M., Piiroinen, J., Asikainen, M., \& Hirvonen, P. (2015). The role of textbooks in Finnish upper secondary school mathematics: Theory, examples and exercises. Nordic Studies in Mathematics Education, 20(3-4), 157-178.

Vincent, J., \& Stacey, K. (2008). Do mathematics textbooks cultivate shallow teaching? Applying the TIMSS Video Study criteria to Australian eighth-grade mathematics textbooks. Mathematics Education Research Journal, 20(1), 82-107.

Wang, Y., \& Fan, L. (2021). Investigating students' perceptions concerning textbook use in mathematics: A comparative study of secondary schools between Shanghai and England. Journal of
Curriculum Studies. https://doi.org/10.1080/00220272.2021. 1941265

Wu, Y., \& Bao, J. (2016). Looking into the typical features of Chinese mathematics classroom from the perspective of Shanghai experience. Modern Teaching, 15(21), 16-17.

Zhang, M., \& Kong, L. (2012). An exploration of reasons for Shanghai's success in the OECD Program for International Student Assessment (PISA) 2009. Frontiers of Education in China, 7(1), $124-162$.

Publisher's Note Springer Nature remains neutral with regard to jurisdictional claims in published maps and institutional affiliations. 